\title{
Her2-Positive and Microsatellite Instability Status in Gastric Cancer-Clinicopathological Implications
}

\author{
Ana Bermúdez ${ }^{1}$, Isabel Arranz-Salas 2,3, Silvia Mercado ${ }^{2}$, Juan A. López-Villodres ${ }^{2}$, Virginia González ${ }^{4}$, \\ Francisca Ríus ${ }^{5}$ (D), María V. Ortega ${ }^{2,3}$, Carmen Alba ${ }^{2}$, Isabel Hierro ${ }^{3}$ and Diego Bermúdez ${ }^{2, * \mathbb{D}}$ \\ 1 Department of Anesthesiology, Nuestra Señora de Valme University Hospital, 41014 Seville, Spain; \\ abermudez@uma.es \\ 2 Department of Human Physiology, Human Histology, Anatomical Pathology and Physical Education, \\ University of Malaga, 29010 Malaga, Spain; iarranz@uma.es (I.A.-S.); smercad@uma.es (S.M.); \\ jantoniolv@uma.es (J.A.L.-V.); mariavi@uma.es (M.V.O.); mcalba@uma.es (C.A.) \\ 3 Unit of Anatomical Pathology, Virgen de la Victoria University Hospital, 29010 Malaga, Spain; ihierro@uma.es \\ 4 Unit of Anatomical Pathology; Montilla Hospital, 14550 Montilla, Spain; \\ virginia.gonzalez.zafra.sspa@juntadeandalucia.es \\ 5 Department of Public Health and Psychiatry, University of Malaga, 29010 Malaga, Spain; rius@uma.es \\ * Correspondence: dbermudez@uma.es
}

check for updates

Citation: Bermúdez, A.; Arranz-Salas, I.; Mercado, S.; López-Villodres, J.A.; González, V.; Ríus, F.; Ortega, M.V.; Alba, C.;

Hierro, I.; Bermúdez, D. Her2-Positive and Microsatellite Instability Status in Gastric Cancer-Clinicopathological Implications. Diagnostics 2021, 11, 944. https://doi.org/10.3390/ diagnostics11060944

Received: 21 April 2021

Accepted: 21 May 2021

Published: 25 May 2021

Publisher's Note: MDPI stays neutral with regard to jurisdictional claims in published maps and institutional affiliations.

Copyright: (c) 2021 by the authors. Licensee MDPI, Basel, Switzerland. This article is an open access article distributed under the terms and conditions of the Creative Commons Attribution (CC BY) license (https:// creativecommons.org/licenses/by/ $4.0 /)$.

\begin{abstract}
Gastric cancer (GC) is one of the leading causes of cancer-related death. The combination of new molecular classifications with clinicopathological data could contribute to the individualization of patients and to the development of new therapeutic strategies. We examined the various associations in two molecular types of GC: HER2-positive (human epidermal growth factor receptor 2) and microsatellite instability (MSI), assessing their influence on treatment and prognosis. A retrospective study of 142 GC patients was performed with molecular characterization through HER2 overexpression and DNA repair protein expression for MSI. The percentage of HER2-positive tumors was 13.4\%, predominantly in men. Correlations were found with intestinal type, metastases, advanced stages and chemotherapy. Almost 75\% of HER2-positive patients died. MSI occurred in $16.2 \%$, associated with advanced age, female sex, distal location and intestinal type. These patients had few metastases and low stages. The percentage of deaths was higher among MSI patients who received perioperative chemotherapy. The determination of HER2 and MSI status in GC is important for their association with specific clinicopathological features and for their prognostic and predictive value.
\end{abstract}

Keywords: gastric cancer; molecular classification; HER2; microsatellite instability; clinicopathological features

\section{Introduction}

Gastric cancer (GC) is the fifth most common malignancy worldwide and a leading cause of cancer-related death [1-13]. Most patients are diagnosed at advanced stages of the disease, making surgery difficult and the prognosis poor [7,8,14-16]. Unlike other tumors, there have been no major advances in GC in terms of survival, which is still less than $30 \%$ at 5 years $[1,5-8,17,18]$. Special mention should be made of HER2-positive cases in which specific treatment with HER2 inhibitors resulted in the first improvements in survival of patients with GC [1,6,9,19-21].

Although different anatomical and histological classifications of GC have been proposed, they lack clinical utility, as they have no prognostic or predictive value $[1,4-7,19]$. Furthermore, it is important to consider cancer not as a single process, but as a set of molecular alterations that can offer different therapeutic targets and treatment strategies, resulting in important advances in other tumor processes [1,22]. GC is a complex, heterogeneous and multifactorial disease [4,7], and its molecular characterization could establish different types to enable the individualization of patients; hence, the importance of the new molecular classifications of GC [8,12,22-26]. 
The Singapore-Duke group first distinguished two types of GC [22] and, subsequently, three types [27]. In 2014, The Cancer Genome Atlas (TCGA) group established four molecular categories of GC: chromosomal instability (CIN), microsatellite instability (MSI), genomically stable (GS) and Epstein-Barr virus-positive (EBV) [28]. This classification was a major advance as it reflects tumor biology and can be associated with certain clinicopathological data [1,4,29]. It is considered of great importance for GC diagnosis [1,4] and for the selection of targeted therapeutic agents $[7,9,19]$. Soon after, the Asian Cancer Research Group (ACRG) [30] identified four types: mesenchymal, MSI, microsatellite stable (MSS) TP53+ and microsatellite stable TP53-, which correlate with the prognosis, as well as with different molecular and disease progression patterns $[9,29]$.

Reviews of GC biomarkers have also been conducted [6,17], although to date only HER2 and PD-L1 (Programmed Death-ligand 1) are able to predict treatment response [9,29,31]. HER2 is the only marker routinely evaluated and widely used for targeted therapy in GC $[2,15-17,19]$. In addition, an immune molecular classification based on tumor microenvironment has recently been proposed [32].

The TCGA classification is the most widely used $[1,3-6,8,9,14,19,23,33,34]$, though there is still a need for a classification that is able to combine molecular patterns with clinical and pathological data for prognostic and predictive utility $[4,5,8,33]$. Nevertheless, the success obtained with anti-HER2 therapies [1,6,21], the use of immune checkpoint inhibitors in some types of GC, and new molecular markers open the door to a combination of classical chemotherapy, immunotherapy and molecular therapy, which could improve outcomes and survival $[9,12,19,25,31,35]$. Pathology laboratories could play an important role in these studies and in the correlation between clinicopathological data with molecular types from a multidisciplinary approach involving oncologists, surgeons and pathologists [21,33].

HER2 is a GC subtype included in the CIN category of the TCGA [28]. It is a protooncogene, a member of the HER family [18,24], encoding a transmembrane receptor with tyrosine kinase activity that regulates proliferation, survival, differentiation, migration and other cellular responses to cancer $[5,6,17]$. Overexpression of HER2 induces malignant transformation and metastasis [24]. HER2-positive GC occurs in a variable percentage $(10-30 \%)$ and is more commonly associated with proximal location, intestinal type, men and advanced age at diagnosis $[1,5-7,9,17,21,36-38]$. Primarily identified in breast cancer, its predictive value has also been established in GC [17]. In addition to trastuzumab, other HER2 inhibitors are being investigated to prevent resistance $[1,7,9,17,19,39]$. Although most studies indicate a worse prognosis in HER2-positive GC, this aspect remains controversial $[1,5,6,17,19,20,24,36,38]$. Microsatellites are repetitive sequences of between one and six nucleotides, located in the DNA, in which genomic instability can occur due to a failure in the mismatch repair (MMR) system performed by DNA repair proteins $[4-7,14,17,19,37]$. MSI accounts for $10-30 \%$ of GC, occurs mainly in the intestinal type, at advanced ages, in women and in the distal stomach. It is associated with low tumor stages, limited lymph node involvement, absence of metastasis and longer survival than in MSS tumors $[1,2,4,7,19,23,29,30,33,40]$. MSI determination is used for prognostic and therapeutic purposes $[6,17,19]$. Survival in MSI GC has been reported to be higher in patients treated with surgery alone, with a worse prognosis in those treated with neoadjuvant chemotherapy $[1,4,7,40-43]$.

It has been suggested that the new molecular classifications of GC in combination with clinicopathological parameters would make it possible to distinguish different groups of patients, improving gastrointestinal oncology and bringing us closer to precision medicine $[1,14,26]$.

Our aim was to correlate HER2-positive and MSI GC subtypes with clinicopathological data to assess whether this could influence treatment or prognosis. 


\section{Materials and Methods}

\subsection{Sample Selection}

This was a retrospective study of all patients diagnosed with GC treated with total or partial gastrectomy at Virgen de la Victoria University Hospital in Malaga (Spain), in the period 2008-2015 ( $n=142)$. Patients were excluded when: $(1)$ we could not access clinical and/or pathological data; (2) the tumor tissue samples obtained were insufficient for the study (thickness less than $50 \mu \mathrm{m}$ ).

\subsection{Clinical and Pathological Data}

The clinicopathological data collected were as follows: age, sex, location, pathological diagnosis, histological type according to the Lauren classification [44], degree of differentiation according to the World Health Organization [45], TNM classification and stage [46], lymphatic, vascular and perineural involvement, perioperative chemotherapy (administered or not) and survival (patient living or deceased).

Tissue samples were formalin-fixed and paraffin-embedded, sectioned, stained with hematoxylin-eosin and assessed by light microscopy.

\subsection{Molecular Data}

For immunohistochemical analysis, six 4- $\mu$ m slices were obtained from each block. Molecular analysis of HER2 was performed by protein overexpression/quantification and of MSI by DNA repair protein expression (MMR).

HER2 protein determination was carried out using the Dako Herceptest ${ }^{\text {TM }}$ kit (Rabbit Anti-Human HER2 Protein antibody) (Dako Denmark A/S, Glostrup, Denmark) on the automated DAKO Autostainer platform. A breast carcinoma with 3+ protein expression for HER2 was selected as a positive control and a breast carcinoma with 0 protein expression for HER2 was selected as a negative control. Cases with Histoscore 3+, in which intense basement membrane and basolateral staining was observed in more than $10 \%$ of the cells, were considered positive overexpression.

Monoclonal antibodies directed against MLH1, MSH2, MSH6 and PMS2 proteins, processed in a DAKO Autostainer, were used for the MSI study. Tonsil tissue was used as a positive control. For each protein, two categories were assessed: preserved expression and loss of expression, depending on whether or not there was any nuclear staining. When this was absent in all tumor cells the tumor was considered to be MSI.

\subsection{Sample Size and Statistical Analysis}

A minimum of 51 patients were required to detect a significant percentage difference of at least $17 \%$ between any two groups in the HER2 and MSI study with all other variables, with $95 \%$ confidence and a power of $80 \%$.

A descriptive analysis of the data was performed, calculating the usual descriptive data for quantitative variables and frequency tables for qualitative variables. For the inferential analysis concerning the presence or absence of MSI and HER2, Student's $t$-test was used for quantitative variables and Pearson's chi-squared test for qualitative variables, after checking homoscedasticity. The mean and standard deviation in the case of Student's $t$-test and percentages of MSI and HER2 were used as descriptors, according to the modalities of the different study variables. Logistic regression analysis was used to examine the relationship between living versus deceased with MSI and chemotherapy. Calculations were performed with SPSS version 24.0, IBM Corp., Armonk, NY, USA, and the difference was considered statistically significant at $p<0.05$.

\section{Results}

\subsection{Study Group. Clinicopathological Features}

The study included 142 patients who underwent gastrectomy for GC, whose clinical, pathological and molecular features, the latter in relation to HER2 and MSI, are shown in Table 1. There were 19 HER2-positive cases (13.4\%) and 23 MSI cases (16.2\%). The mean age 
was 65.41 years, with 89 men and 53 women. The tumor was mainly located in the corpus $(40.8 \%)$ and antrum $(41.5 \%)$. The histological type was intestinal in $53.5 \%$ and diffuse in $40.1 \%$ (Figure 1). There were 104 cases of adenocarcinoma and 34 of signet ring cell carcinoma, with a predominance of G3 differentiation (53.6\%). TNM classification showed a higher frequency of T3 $(40.1 \%)$ and T4 $(30.3 \%)$, with no regional lymph node involvement in $38 \%$ of the cases and no distant metastasis in $90.8 \%$. Most tumors were stage II (33.1\%) and III (32.4\%). There was lymphatic involvement in $45.1 \%$, vascular involvement in $41.5 \%$ and perineural involvement in $33.8 \%$. Chemotherapy was administered to 43 patients $(30.3 \%)$, and at the time of the study 56 patients $(39.4 \%)$ were living.

Table 1. Clinical, pathological and molecular (HER2 positivity and MSI) features of the 142 patients with gastric cancer.

\begin{tabular}{|c|c|c|}
\hline Features & Cases & Percentage $\%$ \\
\hline Age (mean and range) & 65.41 & $34-86$ \\
\hline$\leq 70$ & 83 & $58.45 \%$ \\
\hline$\geq 71$ & 59 & $41.55 \%$ \\
\hline \multicolumn{3}{|l|}{ Molecular characteristics } \\
\hline HER2-positive & 19 & $13.40 \%$ \\
\hline MSI & 23 & $16.20 \%$ \\
\hline \multicolumn{3}{|l|}{ Sex } \\
\hline Male & 89 & $62.70 \%$ \\
\hline Female & 53 & $37.30 \%$ \\
\hline \multicolumn{3}{|l|}{ Location } \\
\hline Cardia & 23 & $16.20 \%$ \\
\hline Fundus & 1 & $0.70 \%$ \\
\hline Corpus & 58 & $40.80 \%$ \\
\hline Antrum & 59 & $41.50 \%$ \\
\hline \multicolumn{3}{|l|}{ Histological type } \\
\hline Intestinal & 76 & $53.50 \%$ \\
\hline Diffuse & 57 & $40.10 \%$ \\
\hline Mixed & 9 & $6.40 \%$ \\
\hline \multicolumn{3}{|l|}{ Pathological diagnosis } \\
\hline Adenocarcinoma & 104 & $73.20 \%$ \\
\hline Signet ring cell carcinoma & 34 & $23.90 \%$ \\
\hline Small cell carcinoma & 2 & $1.40 \%$ \\
\hline Undifferentiated carcinoma & 1 & $0.70 \%$ \\
\hline Squamous cell carcinoma & 1 & $0.70 \%$ \\
\hline \multicolumn{3}{|l|}{ Degree of differentiation } \\
\hline G1 & 18 & $13.00 \%$ \\
\hline G2 & 46 & $33.30 \%$ \\
\hline G3 & 74 & $53.60 \%$ \\
\hline \multicolumn{3}{|l|}{$\mathrm{T}$} \\
\hline Tis & 6 & $4.20 \%$ \\
\hline $\mathrm{T} 1 \mathrm{a} / \mathrm{T} 1 \mathrm{~b}$ & 15 & $10.60 \%$ \\
\hline T2 & 21 & $14.80 \%$ \\
\hline T3 & 57 & $40.10 \%$ \\
\hline $\mathrm{T} 4 \mathrm{a} / \mathrm{T} 4 \mathrm{~b}$ & 43 & $30.30 \%$ \\
\hline \multicolumn{3}{|l|}{$\mathrm{N}$} \\
\hline No & 54 & $38.00 \%$ \\
\hline N1 & 38 & $26.80 \%$ \\
\hline $\mathrm{N} 2$ & 23 & $16.20 \%$ \\
\hline N3a/N3b & 27 & $19.00 \%$ \\
\hline
\end{tabular}


Table 1. Cont.

\begin{tabular}{|c|c|c|}
\hline Features & Cases & Percentage $\%$ \\
\hline \multicolumn{3}{|l|}{$\mathrm{M}$} \\
\hline M0 & 129 & $90.80 \%$ \\
\hline M1 & 13 & $9.20 \%$ \\
\hline \multicolumn{3}{|l|}{ Stage } \\
\hline $\mathrm{IA} / \mathrm{IB}$ & 33 & $23.24 \%$ \\
\hline IIA/IIB & 47 & $33.10 \%$ \\
\hline IIIA/IIIB/IIIC & 46 & $32.40 \%$ \\
\hline IV & 16 & $11.26 \%$ \\
\hline \multicolumn{3}{|c|}{ Lymphatic involvement } \\
\hline Yes & 64 & $45.10 \%$ \\
\hline No & 78 & $54.90 \%$ \\
\hline \multicolumn{3}{|c|}{ Vascular involvement } \\
\hline Yes & 59 & $41.50 \%$ \\
\hline No & 83 & $58.50 \%$ \\
\hline \multicolumn{3}{|c|}{ Perineural involvement } \\
\hline Yes & 48 & $33.80 \%$ \\
\hline No & 94 & $66.20 \%$ \\
\hline \multicolumn{3}{|c|}{ Adjuvant chemotherapy } \\
\hline Yes & 43 & $30.30 \%$ \\
\hline No & 99 & $69.70 \%$ \\
\hline \multicolumn{3}{|l|}{ Survival } \\
\hline Living & 56 & $39.40 \%$ \\
\hline Deceased & 86 & $60.60 \%$ \\
\hline
\end{tabular}

HER2: Human Epidermal Growth Receptor 2, MSI: Microsatellite instability.
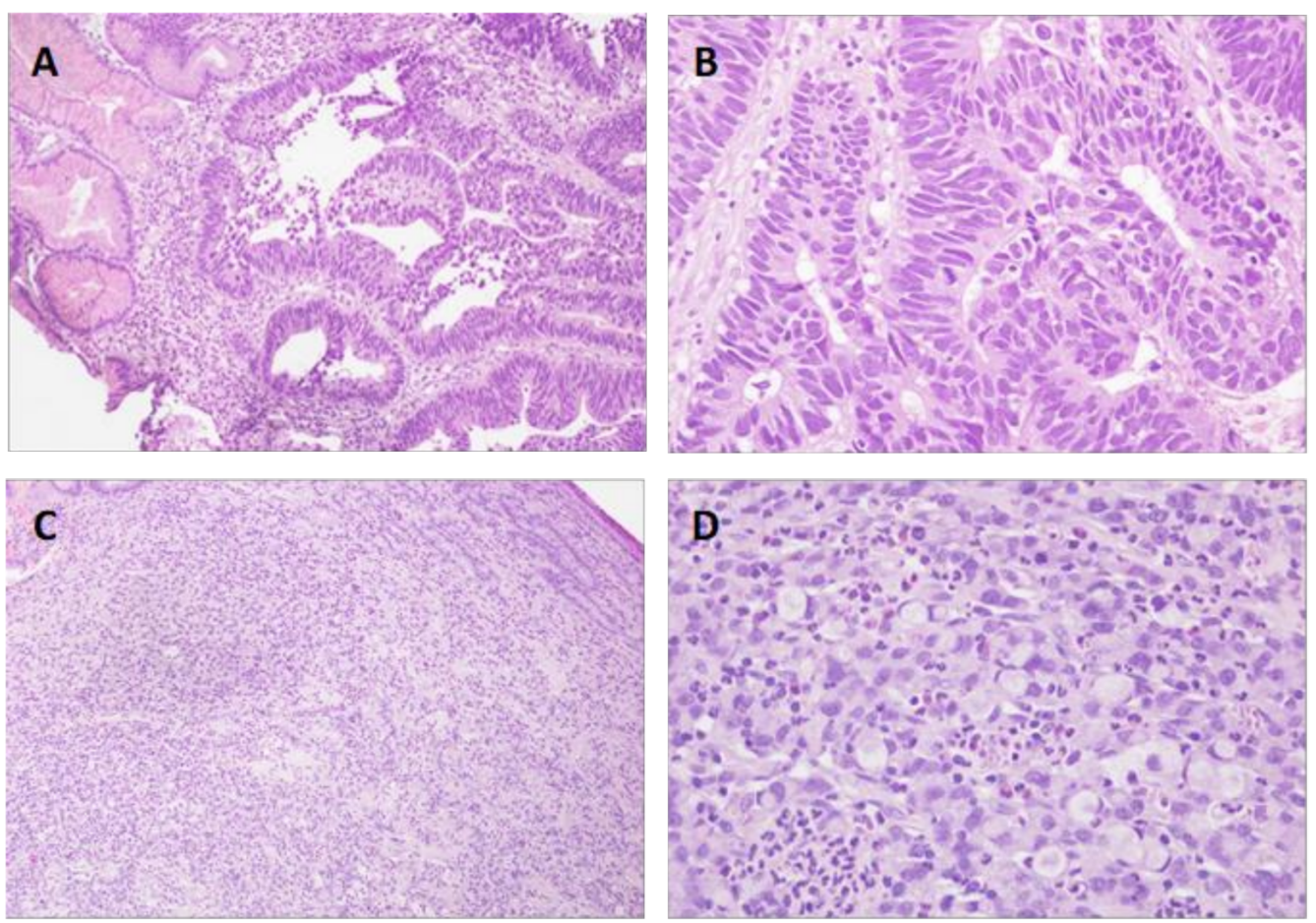

Figure 1. Histological types of gastric cancer according to the Lauren classification. (A,B): Intestinal type. Normal gastric mucosa and tumor nests with intestinal adenocarcinoma morphology are observed ((A), 100×; (B), 400×). (C,D): Diffuse type. There is diffuse infiltration of tumor cells, some with signet ring cell appearance $((C), 100 \times ;(D), 400 \times)$. Hematoxylin-eosin. 


\subsection{HER2-Positive Status and Clinicopathological Features}

Table 2 shows the clinical and pathological features of the 142 GC patients and the correlation with HER2 status (Figure 2). The mean age of HER2-positive cases was slightly lower than that of negative cases (61 versus 66 years), with HER2-positive status in $14.6 \%$ of men and $11.3 \%$ of women. The association with tumor location was statistically significant ( $p=0.041$ ), with HER2 positivity in $4.3 \%$ of GCs located in the cardia, $100 \%$ in the fundus, $13.8 \%$ in the corpus and $5.3 \%$ in the antrum. The correlation with histological type was also significant $(p=0.013)$, with HER2-positive accounting for $21.1 \%$ of the intestinal-type tumors and $11.1 \%$ of the mixed-type tumors.

Table 2. Clinical and pathological features of the 142 gastric cancer patients and correlation with HER2 status.

\begin{tabular}{|c|c|c|c|c|c|}
\hline \multicolumn{2}{|c|}{$\begin{array}{c}\text { HER2-Positive } \\
(n=19)\end{array}$} & \multirow[b]{2}{*}{ Percentage $\%$} & \multicolumn{2}{|c|}{$\begin{array}{c}\text { HER2-Negative } \\
(n=123)\end{array}$} & \multirow[b]{2}{*}{$p$} \\
\hline Features & Cases & & Cases & Percentage $\%$ & \\
\hline Age & & & & & 0.085 \\
\hline Mean & 61 & & 66 & & \\
\hline$\leq 70$ & 14 & $16.86 \%$ & 70 & $84.33 \%$ & \\
\hline$\geq 71$ & 5 & $8.47 \%$ & 53 & $91.53 \%$ & \\
\hline Sex & & & & & 0.578 \\
\hline Male & 13 & $14.60 \%$ & 76 & $85.40 \%$ & \\
\hline Female & 6 & $11.30 \%$ & 47 & $88.70 \%$ & \\
\hline Location & & & & & 0.041 \\
\hline Cardia & 1 & $4.30 \%$ & 22 & $95.70 \%$ & \\
\hline Fundus & 1 & $100 \%$ & 0 & $0.0 \%$ & \\
\hline Corpus & 8 & $13.80 \%$ & 50 & $86.20 \%$ & \\
\hline Antrum & 9 & $15.30 \%$ & 50 & $84.70 \%$ & \\
\hline Histological type & & & & & 0.013 \\
\hline Intestinal & 16 & $21.10 \%$ & 60 & $78.90 \%$ & \\
\hline Diffuse & 2 & $3.50 \%$ & 55 & $96.50 \%$ & \\
\hline Mixed & 1 & $11.10 \%$ & 9 & $88.90 \%$ & \\
\hline Pathological diagnosis & & & & & 0.267 \\
\hline Adenocarcinoma & 18 & $17.30 \%$ & 86 & $82.70 \%$ & \\
\hline $\begin{array}{l}\text { Signet ring cell } \\
\text { carcinoma }\end{array}$ & 1 & $2.90 \%$ & 33 & $97.10 \%$ & \\
\hline Small cell carcinoma & 0 & $0.00 \%$ & 2 & $100 \%$ & \\
\hline $\begin{array}{l}\text { Undifferentiated } \\
\text { carcinoma }\end{array}$ & 0 & $0.00 \%$ & 1 & $100 \%$ & \\
\hline $\begin{array}{l}\text { Squamous cell } \\
\text { carcinoma }\end{array}$ & 0 & $0.00 \%$ & 1 & $100 \%$ & \\
\hline Degree of differentiation & & & & & 0.178 \\
\hline G1 & 0 & $0.00 \%$ & 18 & $100 \%$ & \\
\hline $\mathrm{G} 2$ & 8 & $17.40 \%$ & 38 & $82.60 \%$ & \\
\hline G3 & 11 & $14.90 \%$ & 63 & $85.10 \%$ & \\
\hline $\mathrm{T}$ & & & & & 0.25 \\
\hline Tis & 0 & $0.00 \%$ & 6 & $100 \%$ & \\
\hline $\mathrm{T} 1 \mathrm{a} / \mathrm{T} 1 \mathrm{~b}$ & 0 & $0.00 \%$ & 15 & $100 \%$ & \\
\hline $\mathrm{T} 2$ & 1 & $4.80 \%$ & 20 & $95.20 \%$ & \\
\hline $\mathrm{T} 3$ & 11 & $19.30 \%$ & 46 & $80.70 \%$ & \\
\hline $\mathrm{T} 4 \mathrm{a} / \mathrm{T} 4 \mathrm{~b}$ & 7 & $16.27 \%$ & 36 & $83.73 \%$ & \\
\hline
\end{tabular}


Table 2. Cont.

\begin{tabular}{|c|c|c|c|c|c|}
\hline \multicolumn{2}{|c|}{$\begin{array}{l}\text { HER2-Positive } \\
\quad(n=19)\end{array}$} & \multirow[b]{2}{*}{ Percentage $\%$} & \multicolumn{2}{|c|}{$\begin{array}{c}\text { HER2-Negative } \\
\quad(n=123)\end{array}$} & \multirow[b]{2}{*}{$p$} \\
\hline Features & Cases & & Cases & Percentage $\%$ & \\
\hline $\mathrm{N}$ & & & & & 0.455 \\
\hline No & 5 & $9.30 \%$ & 49 & $90.70 \%$ & \\
\hline N1 & 5 & $13.20 \%$ & 33 & $86.80 \%$ & \\
\hline N2 & 3 & $13.00 \%$ & 20 & $87.00 \%$ & \\
\hline N3a/N3b & 6 & $22.20 \%$ & 21 & $77.80 \%$ & \\
\hline M & & & & & 0.005 \\
\hline M0 & 14 & $10.90 \%$ & 115 & $89.10 \%$ & \\
\hline M1 & 5 & $38.50 \%$ & 8 & $61.50 \%$ & \\
\hline Stage & & & & & 0.012 \\
\hline $\mathrm{IA} / \mathrm{IB}$ & 1 & $3.10 \%$ & 32 & $96.90 \%$ & \\
\hline IIA/IIB & 6 & $12.80 \%$ & 41 & $87.20 \%$ & \\
\hline IIIA/IIIB/IIIC & 6 & $13.00 \%$ & 40 & $87.00 \%$ & \\
\hline IV & 6 & $37.50 \%$ & 10 & $62.50 \%$ & \\
\hline Lymphatic involvement & & & & 0.227 & \\
\hline Yes & 11 & $17.20 \%$ & 53 & $82.80 \%$ & \\
\hline No & 8 & $10.30 \%$ & 70 & $89.70 \%$ & \\
\hline Vascular involvement & & & & 0.292 & \\
\hline Yes & 10 & $16.90 \%$ & 49 & $83.10 \%$ & \\
\hline No & 9 & $10.80 \%$ & 74 & $89.20 \%$ & \\
\hline Perineural involvement & & & & 0.763 & \\
\hline Yes & 7 & $14.60 \%$ & 41 & $85.40 \%$ & \\
\hline No & 12 & $12.80 \%$ & 82 & $87.20 \%$ & \\
\hline Adjuvant chemotherapy & & & & 0.005 & \\
\hline Yes & 11 & $25.60 \%$ & 32 & $74.40 \%$ & \\
\hline No & 8 & $8.10 \%$ & 91 & $91.90 \%$ & \\
\hline Survival & & & & 0.209 & \\
\hline Living & 5 & $8.90 \%$ & 51 & $91.10 \%$ & \\
\hline Deceased & 14 & $16.30 \%$ & 72 & $83.70 \%$ & \\
\hline
\end{tabular}

HER2: Human Epidermal Growth Receptor 2.

Eighteen cases of adenocarcinoma were HER2-positive, as were $17.4 \%$ of G2 tumors, $14.9 \%$ of G3 tumors, $19.3 \%$ of T3 tumors, and $16.27 \%$ of T4 tumors, with lymph node involvement in 14 of the 19 cases. There was a significant association with metastases ( $p=0.005)$, such that although 14 HER2-positive patients had no metastases, of the 13 patients in the series who had metastases, five were HER2-positive. The majority of cases were classified as stage III and IV ( $p=0.012)$. HER2 positivity was found in $17.2 \%$ of patients with lymphatic involvement, $16.9 \%$ with vascular involvement and $14.6 \%$ with perineural involvement. The administration of adjuvant chemotherapy was significantly correlated ( $p=0.005$ ), with $25.6 \%$ of the patients receiving chemotherapy being HER2-positive. Of the total deceased, $16.3 \%$ had HER2-positive tumors, which corresponded to 14 of the 19 HER2-positive cases.

\subsection{MSI Status and Clinicopathological Features}

Table 3 provides the clinical and pathological features of the 142 GC patients and the correlation with MSI status (Figure 3). Age showed a statistically significant correlation $(p<0.0001)$, with the mean age of MSI cases being higher than that of MSS cases (75.43 versus 63.48 years). There was also a significant association with sex $(p=0.038)$, location $(p=0.015)$ and histological type $(p=0.033)$, with $24.5 \%$ of women, $27.1 \%$ of antrum tumors and $23.7 \%$ of intestinal-type tumors displaying MSI. 

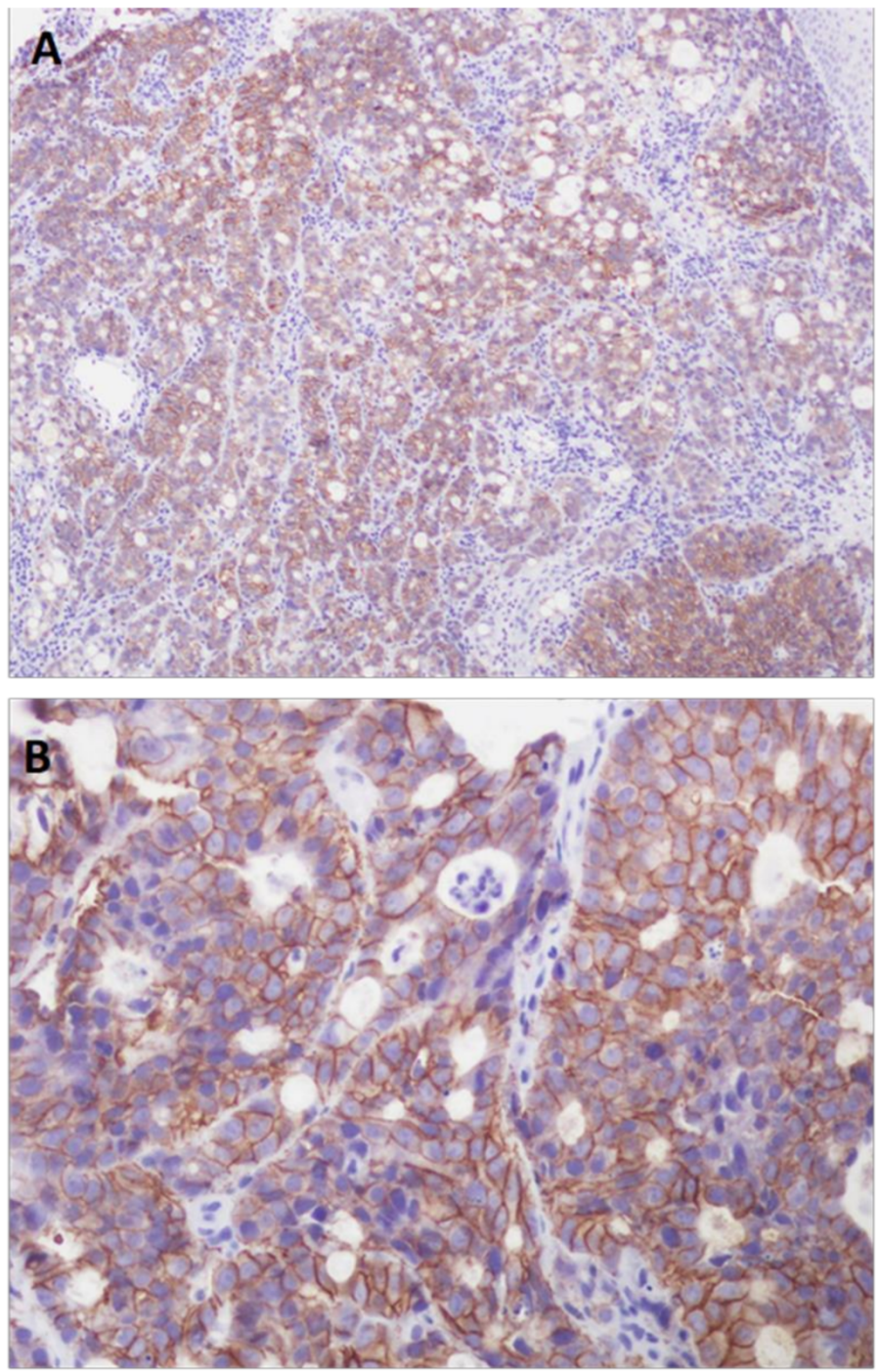

Figure 2. HER2-positive gastric cancer (Histoscore 3+). (A,B): Immunohistochemical technique showing intense basement membrane and basolateral staining in more than $10 \%$ of the cells ((A), 100×; (B), $400 \times)$ ).

Table 3. Clinical and pathological features of the 142 gastric cancer patients and correlation with MSI status.

\begin{tabular}{cccccc}
\hline Features & $\begin{array}{c}\text { MSI }(\boldsymbol{n}=\mathbf{2 3}) \\
\text { Cases }\end{array}$ & Percentage $\%$ & Cases & Percentage $\%$ & $p$ \\
\hline Age & & & & & $<0.0001$ \\
Mean & 75.43 & & 63.48 & & \\
$\leq 70$ & 2 & $2.40 \%$ & 81 & $97.60 \%$ & \\
$\geq 71$ & 21 & $35.59 \%$ & 38 & $64.41 \%$ & \\
Sex & & & & & 0.038 \\
Male & 10 & $11.20 \%$ & 79 & $88.80 \%$ & \\
Female & 13 & $24.50 \%$ & 40 & $75.50 \%$ & \\
Location & & & & & \\
Cardia & 0 & $0.00 \%$ & 23 & $100.00 \%$ & \\
Fundus & 0 & $0.00 \%$ & 1 & $100.00 \%$ & \\
Corpus & 7 & $12.10 \%$ & 51 & $89.70 \%$ & \\
Antrum & 16 & $27.10 \%$ & 43 & $72.90 \%$ & \\
\hline
\end{tabular}


Table 3. Cont.

\begin{tabular}{|c|c|c|c|c|c|}
\hline \multicolumn{2}{|c|}{ MSI $(n=23)$} & \multicolumn{4}{|c|}{ MSS $(n=119)$} \\
\hline Features & Cases & Percentage $\%$ & Cases & Percentage $\%$ & $p$ \\
\hline Histological type & & & & & 0.033 \\
\hline Intestinal & 18 & $23.70 \%$ & 58 & $76.30 \%$ & \\
\hline Diffuse & 4 & $7.00 \%$ & 53 & $93.00 \%$ & \\
\hline Mixed & 1 & $11.10 \%$ & 8 & $88.90 \%$ & \\
\hline Pathological diagnosis & & & & & 0.324 \\
\hline Adenocarcinoma & 21 & $20.20 \%$ & 83 & $79.80 \%$ & \\
\hline $\begin{array}{l}\text { Signet ring cell } \\
\text { carcinoma }\end{array}$ & 2 & $5.90 \%$ & 32 & $94.10 \%$ & \\
\hline Small cell carcinoma & 0 & $0.00 \%$ & 2 & $100.00 \%$ & \\
\hline $\begin{array}{l}\text { Undifferentiated } \\
\text { carcinoma }\end{array}$ & 0 & $0.00 \%$ & 1 & $100.00 \%$ & \\
\hline $\begin{array}{l}\text { Squamous cell } \\
\text { carcinoma }\end{array}$ & 0 & $0.00 \%$ & 1 & $100.00 \%$ & \\
\hline Degree of differentiation & & & & & 0.122 \\
\hline G1 & 6 & $33.30 \%$ & 12 & $66.70 \%$ & \\
\hline G2 & 6 & $13.00 \%$ & 40 & $87.00 \%$ & \\
\hline G3 & 11 & $14.90 \%$ & 63 & $85.10 \%$ & \\
\hline $\mathrm{T}$ & & & & & 0.593 \\
\hline Tis & 2 & $33.30 \%$ & 4 & $66.70 \%$ & \\
\hline $\mathrm{T} 1 \mathrm{a} / \mathrm{T} 1 \mathrm{~b}$ & 2 & $13.30 \%$ & 13 & $86.70 \%$ & \\
\hline $\mathrm{T} 2$ & 5 & $23.80 \%$ & 16 & $76.20 \%$ & \\
\hline T3 & 7 & $12.30 \%$ & 50 & $87.70 \%$ & \\
\hline $\mathrm{T} 4 \mathrm{a} / \mathrm{T} 4 \mathrm{~b}$ & 7 & $16.27 \%$ & 36 & $83.73 \%$ & \\
\hline $\mathrm{N}$ & & & & & 0.647 \\
\hline No & 11 & $20.40 \%$ & 43 & $79.60 \%$ & \\
\hline N1 & 4 & $10.50 \%$ & 34 & $89.50 \%$ & \\
\hline N2 & 4 & $17.40 \%$ & 19 & $82.60 \%$ & \\
\hline N3a/N3b & 4 & $14.80 \%$ & 23 & $85.20 \%$ & \\
\hline $\mathrm{M}$ & & & & & 0.383 \\
\hline M0 & 22 & $17.10 \%$ & 107 & $82.90 \%$ & \\
\hline M1 & 1 & $7.70 \%$ & 12 & $92.30 \%$ & \\
\hline Stage & & & & & 0.555 \\
\hline $\mathrm{IA} / \mathrm{IB}$ & 5 & $15.20 \%$ & 28 & $84.80 \%$ & \\
\hline IIA/IIB & 10 & $21.30 \%$ & 37 & $78.72 \%$ & \\
\hline IIIA/IIIB/IIIC & 7 & $15.20 \%$ & 39 & $84.80 \%$ & \\
\hline IV & 1 & $6.30 \%$ & 15 & $93.70 \%$ & \\
\hline Lymphatic involvement & & & & 0.532 & \\
\hline Yes & 9 & $14.10 \%$ & 55 & $85.90 \%$ & \\
\hline No & 14 & $17.90 \%$ & 64 & $82.10 \%$ & \\
\hline Vascular involvement & & & & 0.797 & \\
\hline Yes & 9 & $15.30 \%$ & 50 & $84.70 \%$ & \\
\hline No & 14 & $16.90 \%$ & 69 & $83.10 \%$ & \\
\hline Perineural involvement & & & & 0.914 & \\
\hline Yes & 8 & $16.70 \%$ & 40 & $83.30 \%$ & \\
\hline No & 15 & $16.00 \%$ & 79 & $84.00 \%$ & \\
\hline Adjuvant chemotherapy & & & & 0.33 & \\
\hline Yes & 5 & $11.60 \%$ & 38 & $88.40 \%$ & \\
\hline No & 18 & $18.20 \%$ & 81 & $81.80 \%$ & \\
\hline Survival & & & & 0.618 & \\
\hline Living & 8 & $14.30 \%$ & 48 & $85.70 \%$ & \\
\hline Deceased & 15 & $17.40 \%$ & 71 & $82.60 \%$ & \\
\hline
\end{tabular}

MSI: Microsatellite instability; MSS: Microsatellite stability. 

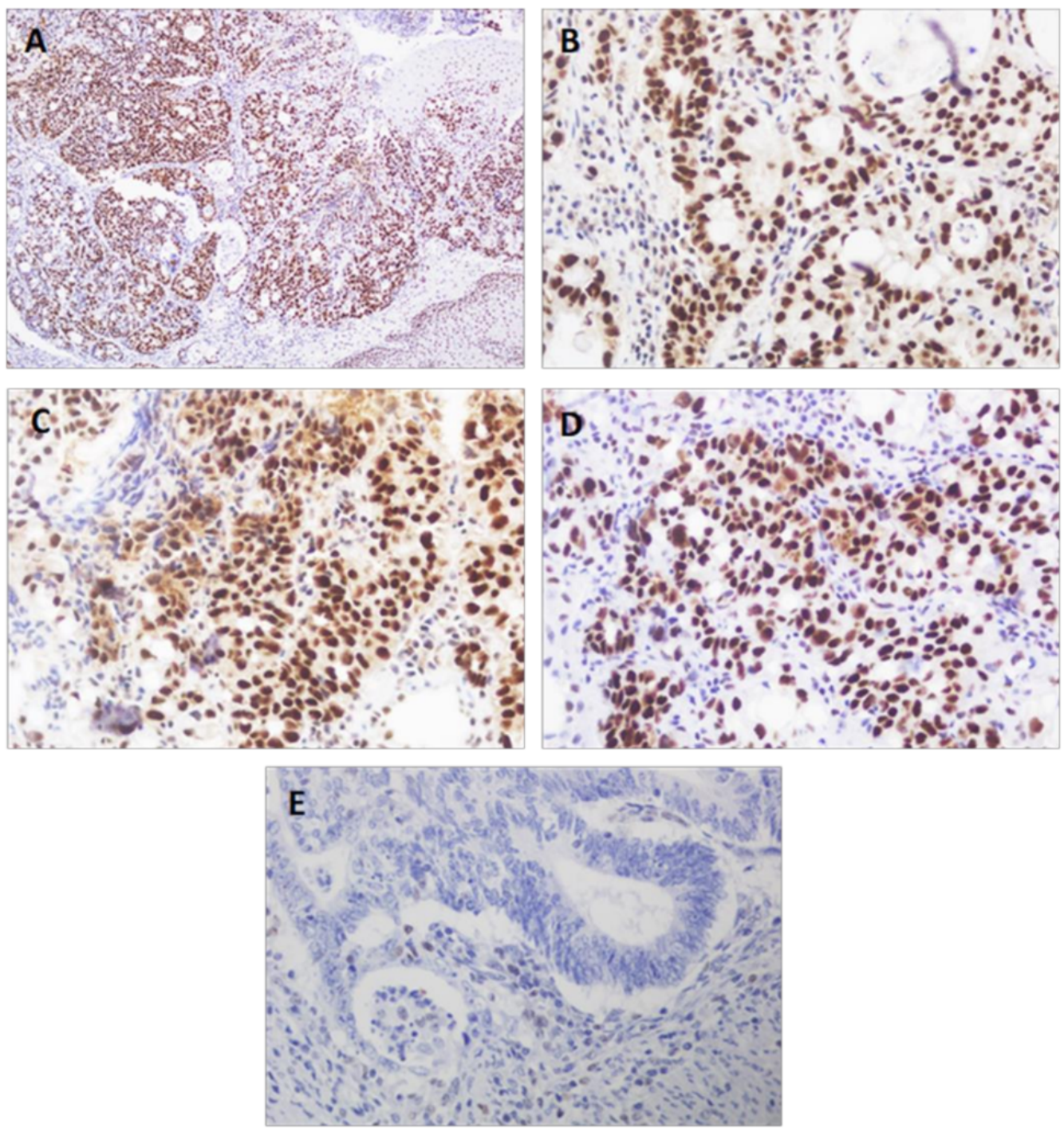

Figure 3. Gastric cancer. Immunohistochemical staining for DNA repair proteins. Preserved immunoexpression of MLH1 ((A), 100×), MLH2 ((B), 400×), MSH6 ((C), 400×) and PMS2 ((D), 400× ) proteins. (E): Loss of MLH1 expression in tumor cells (positive internal control in accompanying lymphocytes) $(400 \times)$.

Correlation with the degree of differentiation, tumor size, lymph node involvement, metastases, stages and lymphatic, vascular or perineural involvement showed no significant results. However, of the 23 patients with MSI, 11 had no lymph node involvement, one had metastases and 15 were stage I/II.

Of the 43 patients who received chemotherapy, five were MSI (11.6\%), while of the 99 patients who did not receive chemotherapy, 18 had MSI tumors (18.2\%). Of those who died, $17.4 \%$ were MSI. Logistic regression of MSI, chemotherapy and survival showed no significant results, although of the five patients with MSI who had received chemotherapy, four had died (Table 4). 
Table 4. Association of MSI status with perioperative chemotherapy administration and survival. MSI: microsatellite instability; MSS: microsatellite stability.

\begin{tabular}{cccccc}
\hline Status & MSI & & & MSS & \\
& Living & Deceased & Living & Deceased & $p$ \\
\hline Chemotherapy & $1(20 \%)$ & $4(80 \%)$ & $15(39.5 \%)$ & $23(60.5 \%)$ & 0.397 \\
Surgery alone & $7(38.9 \%)$ & $11(61.1 \%)$ & $33(40.7 \%)$ & $48(59.3 \%)$ & 0.885 \\
\hline
\end{tabular}

MSI: Microsatellite instability; MSS: Microsatellite stability.

Two patients were both HER2-positive and MSI concurrently. Table 5 shows the clinical and pathological features of the gastric cancer patients showing both HER2-positive and MSI status, highlighting the match in most parameters.

Table 5. Clinical and pathological features of the gastric cancer patients showing both HER2-positive and MSI status.

\begin{tabular}{ccc}
\hline Features & \multicolumn{2}{c}{ HER2-Positive and MSI $(\boldsymbol{n}=\mathbf{2})$} \\
& Case $\mathbf{1}$ & Case 2 \\
\hline Age & 76 & 74 \\
Sex & Female & Male \\
Location & Antrum & Antrum \\
Histological type & Intestinal & Intestinal \\
Pathological diagnosis & Adenocarcinoma & Adenocarcinoma \\
Degree of differentiation & G3 & G3 \\
T & T3 & T3 \\
N & N3a & N0 \\
M & M1 & M0 \\
Stage & IV & IIA \\
Lymphatic involvement & Yes & Yes \\
Vascular involvement & Yes & Yes \\
Perineural involvement & Yes & Yes \\
Adjuvant chemotherapy & No & No \\
Survival & Deceased & Deceased \\
\hline
\end{tabular}

HER2: Human Epidermal Growth Receptor 2, MSI: Microsatellite instability.

\section{Discussion}

Gastric cancer is one of the leading causes of cancer and death globally [1-9,14,15,17], although its considerable heterogeneity hinders the individualization of patients that precision medicine would require $[1,5,14,29,34,36]$. For this reason, the traditional classifications have been superseded by the greater clinical utility of the new molecular classifications $[28,30]$. In this study, we examined a series of 142 GC cases, in which HER2 and MSI markers were determined and correlated with clinicopathological data to assess whether, as proposed, this could have an influence on treatment or prognosis $[4,5,8,31,33]$.

Although recent advances in molecular biology advances have been made, they do not yet lead to a choice in treatment approach except in advanced disease with overexpression of HER2 [46].

The clinicopathological features of GC patients (Table 1) are: advanced mean age (65.41 years), predominance of men $(62.7 \%)$, intestinal histological type $(53.5 \%)$ and location in the corpus $(40.8 \%)$ and antrum $(41.5 \%)$, as well as stages II $(33.1 \%)$ and III $(32.4 \%)$. These data are comparable to those of previous observations $[1,5,23,29,40]$, although in recent decades there has been a decrease in the intestinal type and distal location [47].

The proportion of HER2 positivity in our series was $13.4 \%$, results that are very similar to those obtained by other authors in Europe and Asia [29,36,38], which would support the theory that no geographical differences exist [21,37]. Nonetheless, variable figures $(6-38 \%)$ have been published according to the location and histology of the tumor $[1,5-7,9,17,20,24]$. Other factors, such as the type of sample (biopsy or surgical specimen) or the criteria for positivity, may also play a role $[20,21,36,48]$. In our study, we exclusively used gastrectomy specimens, and only cases with $3+$ protein expression were considered positive. 
The $16.2 \%$ MSI percentage is within the $15-30 \%$ range previously reported $[1,4,6,23,28,30]$, although lower figures have also been described $[29,40,43]$. This variability could be due to patient and sample selection, intra-tumoral heterogeneity, as well as methodological and possibly geographic differences $[3,40,43]$, with a higher prevalence in the Western population than in the Asian population [10].

\subsection{HER2-Positive Status and Clinicopathological Features}

The mean age of patients with HER2-positive GC in our study was 61 years, with more than twice as many men as women, as in other publications [36,37]. This type of tumor appeared mainly located in the corpus and antrum, in contrast to findings of other authors, which associate HER2 positivity with proximal location, especially in the gastroesophageal junction $[1,21,37,38,48]$. However, our data agree with those reported in one study [36], and a lack of correlation between HER2 status and location has also been communicated [43]. This discrepancy could be due to the low percentage of proximal neoplasms in our series, since tumors of the gastroesophageal junction and some tumors of the proximal stomach are classified as esophageal cancer $[40,49]$.

There is a relevant association with histological type, with HER2-positive accounting for $21.1 \%$ of intestinal-type tumors, which coincides with published percentages of $13.7-34 \%[1,2,6,21,38]$. Our data confirm that, as reported [36,37], more than $80 \%$ of patients with HER2-positive GC have intestinal-type tumors. The degree of differentiation, TNM classification, staging and lymphatic, vascular or perineural involvement have no or unclear correlation with HER2 overexpression [17,36-38]. Our study confirms these aspects, with the exception of metastases and staging, which do correlate, since five of the 13 patients in our series who had metastases were HER2-positive and the majority of cases were in advanced stages, possibly due to a greater aggressiveness of the tumor [19].

Regarding survival, although not statistically significant, it is important to note that $16.3 \%$ of the deceased had HER2-positive GC and that almost 75\% of the HER2-positive patients died, which together with the data on metastasis and advanced stages would corroborate the poor prognosis associated with this type of GC, although a clear consensus is still lacking $[1,5,6,19,36,38,48]$. The correlation with the administration of chemotherapy could be related to the standard treatment with a trastuzumab-containing regimen $[1,5,6,9]$, as HER2 status predicts prognosis and sensitivity to anti-HER2 agents [46,50].

\subsection{MSI Status and Clinicopathological Features}

The mean age of our patients with MSI was 75 years (10 years more for GC), similar to that of the TCGA study [28]; 21 of the 23 cases were older than 70 years, with a marked correlation that corroborates the connection between MSI and advanced age [3,23,29,31,40,43,51-53]. It has been noted that, despite the higher incidence of GC in men, the MSI type is more frequent in women [1-4,16,23,28,40,43,51-53]; this is demonstrated by its association with sex, as 13 of the 23 cases of MSI were women. The tumor appears to be associated with a distal or mid/lower location, mainly in the antrum, which is consistent with data from the literature $[1,2,23,30,31,40,43,51-53]$.

Our results show that MSI GC is mainly of the intestinal type (78.3\% of MSI cases), data similar to those of other authors [16,23,28,51], although different figures have also been published $[2,29,30,40]$, which could be due to methodological and geographical differences $[43,53]$. The degree of differentiation, tumor size and lymphatic, vascular or perineural involvement were not associated with MSI status, as has been previously reported $[23,40]$. The same was found with lymph node involvement, metastases and stages. However, almost half of our MSI patients had no lymph node involvement, only one had metastases and two thirds had a low stage, which is in line with other studies $[23,30,34,40,51,53]$ and could be considered clinically relevant and related to the prognosis.

No significant association was found between MSI status, perioperative chemotherapy and survival, although $80 \%$ of the patients with MSI who underwent chemotherapy died compared to $61 \%$ of those treated with surgery alone, and there was no such difference 
in patients with MSS. Of all GCs, MSI has been highlighted as having the best prognosis $[10,22,28,30,33,40,51-54]$, especially in patients undergoing surgery alone, with a worse prognosis when neoadjuvant chemotherapy is used $[1,4,7,40-43]$. These data emphasize the prognostic and predictive role of the MSI marker, as has been noted $[6,17,19]$ and, although further studies will be needed, it could be of interest to consider MSI determination before initiating chemotherapy, since, in these MSI cases (and also in EBV), chemotherapy does not improve survival [55]. Our study is retrospective, but it is possible that, in some cases of MSI GC, the use of chemotherapy could have been avoided.

Nevertheless, the low incidence of MSI GC indicates that the total number of cases studied continues to be low, so the debate remains open [56,57]. Additionally, the MSI and EBV subtypes of GC have been associated with a good response to immunotherapy $[1,12,35,51,54-57]$. This approach may be of therapeutic importance, due to the use of immune checkpoint inhibitors, although it has not yet been fully demonstrated in the first or second line [1,46]. Additionally, pembrolizumab monotherapy can only be considered in MSI patients who had previously received at least two lines of treatment, as shown by the high response rate achieved by these patients [58]. Although a high rate of PD-L1 expression has been reported in cases of MSI GC $[1,6,9,19]$, this biomarker may be considered for the use of immune checkpoint inhibitors [59]. In any case, it is important to note that pembrolizumab in MSI cancer cases was the first treatment approved by the FDA according to the type of biomarker, regardless of the anatomical location of the tumor $[30,34]$.

Two of the 142 patients showed HER2-positive and MSI status concurrently, with similar clinicopathological characteristics in both cases, although there were some differences. Both patients, male and female, deceased, were over 71 years of age and were not treated with adjuvant chemotherapy. The tumor was adenocarcinoma located in the antrum, of intestinal type, with G3 differentiation grade, and lymphatic, vascular and perineural involvement. One case was in stage IIA, showing no metastasis or lymph node involvement, and the other patient was in stage IV, exhibiting metastasis and lymph node implication. Several cases of patients showing HER2-positive and MSI/PD-L1-positive concomitant GC have been reported [60]. Moreover, a significant number of HER2-mutated and ERBB3-mutated samples associated with MSI have been found in metastatic colorectal cancer, theorizing the possibility of combining immunotherapy with anti-HER2 agents for these patients [61].

Molecular classification of the GC is a useful tool for treatment. It is necessary to identify the subgroups that can benefit the most from specific treatments and immunotherapy, together with strategies to avoid the immunosuppression that occurs in a high percentage of CGs [62]. Our study comprised limited casuistry and has only determined the HER2 and MSI subtypes, but the integration of molecular and clinicopathological data could help to develop targeted therapies and identify predictive and prognostic markers. Although, with the exception of HER2, the new biomarkers are not yet integrated into daily clinical practice, the importance of their determination should be emphasized, especially if we take into account that, as we have confirmed for HER2 and MSI, they are associated with specific clinicopathological features of the patients. HER2 testing should always be conducted to select patients with metastatic disease for specific treatment and MSI should be tested in advanced GC to predict the clinical benefit of immune checkpoint inhibitors [46]. The future of gastrointestinal oncology needs new research to establish different patient groups, early diagnosis and new therapeutic strategies. We are extending the characterization of HER2 and MSI molecular types to new GC patients and starting EBV determination through in situ hybridization. We hope that future studies on the integration of molecular and clinicopathological data in GC will contribute to the progress in the identification of prognostic and predictive biomarkers, as well as in the development of specific therapeutic strategies. 


\section{Conclusions}

In conclusion, the general clinicopathological features of our GC patients are advanced age, male sex, intestinal type, proximal location and stages II-III. Tumors were HER2-positive in $13.4 \%$ and MSI in $16.2 \%$, and they were associated with certain clinicopathological characteristics. The determination of HER2 and MSI status in GC is relevant for precision oncology. HER2 positivity was associated with intestinal type, metastasis and advanced tumor stages. More than twice as many HER2-positive GC patients were men, and most of them died. It was associated with a poor prognosis. Microsatellite instability was correlated with advanced age, female sex, distal location and intestinal type. There were few lymph node and distant metastases, with a predominance of early tumor stages. The percentage of deaths was lower if treated with surgery alone. It was associated with a better prognosis. The data supports the importance of determining HER2 and MSI status in GC, considering that they are not always routinely evaluated.

Author Contributions: Conceptualization, A.B., I.A.-S. and D.B.; methodology, I.A.-S., S.M., F.R. and D.B.; software, F.R.; investigation, A.B., F.R., I.A.-S., V.G., M.V.O. and I.H; resources and data curation, C.A. and J.A.L.-V.; writing-original draft preparation, A.B., J.A.L.-V., M.V.O. and S.M.; writing-review and editing, I.A.-S., D.B. and I.H.; project administration, D.B. All authors have read and agreed to the published version of the manuscript.

Funding: This research was financially supported by the Department of Human Physiology, Human Histology, Anatomical Pathology and Physical Education (Histology Unit), University of Malaga and by the Department of Anatomical Pathology, Virgen de la Victoria University Hospital.

Institutional Review Board Statement: The study was conducted according to the Declaration of Helsinki, national and international guidelines and approved by the Provincial Research Ethics Committee of Malaga, Spain (approval 21 February 2019, number TFG-NCCG-2019).

Informed Consent Statement: All the subjects provided written informed consent before participating in the study. Written informed consent for publication obtained from participating patients who can be identified.

Data Availability Statement: The data that support the findings of this study are available from the corresponding author upon reasonable request.

Acknowledgments: The authors would like to thank Maria Repice for her help with the English version of the text.

Conflicts of Interest: The authors declare no conflict of interest. The funders had no role in the design of the study; in the collection, analyses, or interpretation of data; in the writing of the manuscript, or in the decision to publish the results.

\section{References}

1. Garattini, S.K.; Basile, D.; Cattaneo, M.; Fanotto, V.; Ongaro, E.; Bonotto, M.; Negri, F.V.; Berenato, R.; Ermacora, P.; Cardellino, G.G.; et al. Molecular classifications of gastric cancers: Novel insights and possible future applications. World J. Gastrointest. Oncol. 2017, 9, 194-208. [CrossRef] [PubMed]

2. Birkman, E.M.; Mansuri, N.; Kurki, S.; Ålgars, A.; Lintunen, M.; Ristamäki, R.; Sundström, J.; Carpén, O. Gastric cancer: Immunohistochemical classification of molecular subtypes and their association with clinicopathological characteristics. Virchows Arch. 2018, 472, 369-382. [CrossRef] [PubMed]

3. Polom, K.; Marano, L.; Marrelli, D.; De Luca, R.; Roviello, G.; Savelli, V.; Tan, P.; Roviello, F. Meta-analysis of microsatellite instability in relation to clinicopathological characteristics and overall survival in gastric cancer. Br. J. Surg. 2018, 105, 159-167. [CrossRef] [PubMed]

4. Alessandrini, L.; Manchi, M.; De Re, V.; Dolcetti, R.; Canzonieri, V. Proposed Molecular and miRNA Classification of Gastric Cancer. Int. J. Mol. Sci. 2018, 19, 1683. [CrossRef]

5. Gullo, I.; Carneiro, F.; Oliveira, C.; Almeida, G.M. Heterogeneity in Gastric Cancer: From Pure Morphology to Molecular Classifications. Pathobiology 2017, 85, 50-63. [CrossRef]

6. Matsuoka, T.; Yashiro, M. Biomarkers of gastric cancer: Current topics and future perspective. World J. Gastroenterol. 2018, 24, 2818-2832. [CrossRef]

7. Cisło, M.; Filip, A.A.; Arnold Offerhaus, G.J.; Ciseł, B.; Rawicz-Pruszyński, K.; Skierucha, M.; Polkowski, W.P. Distinct molecular subtypes of gastric cancer: From Laurén to molecular pathology. Oncotarget 2018, 9, 19427-19442. [CrossRef] 
8. Owen, G.I.; Pinto, M.P.; Retamal, I.N.; Fernádez, M.F.; Cisternas, B.; Mondaca, S.; Sanchez, C.; Galindo, H.; Nervi, B.; Ibañez, C.; et al. Chilean Gastric Cancer Task Force. A study protocol to obtain a clinical and molecular classification of a cohort of gastric cancer patients. Medicine 2018, 97, 16. [CrossRef]

9. Kankeu Fonkoua, L.; Yee, N.S. Molecular Characterization of Gastric Carcinoma: Therapeutic Implications for Biomarkers and Targets. Biomedicines 2018, 6, 32. [CrossRef]

10. Serra, O.; Galán, M.; Ginesta, M.M.; Calvo, M.; Salad, N.; Salazar, R. Comparison and applicability of molecular classifications for gastric cancer. Cancer Treat. Rev. 2019, 77, 29-34. [CrossRef]

11. Lu, S.; Wang, L.J.; Lombardo, K.; Kwak, Y.; Kim, W.H.; Resnick, M.B. Expression of Indoleamine 2, 3-dioxygenase 1 (IDO1) and Tryptophanyl-tRNA Synthetase (WARS) in Gastric Cancer Molecular Subtypes. Appl. Immunohistochem. Mol. Morphol. 2020, 28, 360-368. [CrossRef]

12. Magalhães, H.; Fontes-Sousa, M.; Machado, M. Immunotherapy in Advanced Gastric Cancer: An Overview of the Emerging Strategies. Can. J. Gastroenterol. Hepatol. 2018, 27, 32408. [CrossRef] [PubMed]

13. Bray, F.; Ferlay, J.; Soerjomataram, I.; Siegel, R.L.; Torre, L.A.; Jemal, A. Global cancer statistics 2018: GLOBOCAN estimates of incidence and mortality worldwide for 36 cancers in 185 countries. CA Cancer J. Clin. 2018, 68, 394-424. [CrossRef] [PubMed]

14. Maleki, S.S.; Röcken, C. Chromosomal Instability in Gastric Cancer. Neoplasia 2017, 19, 412-420. [CrossRef] [PubMed]

15. Chia, N.Y.; Tan, P. Molecular classification of gastric cancer. Ann. Oncol. 2016, 27, 763-769. [CrossRef] [PubMed]

16. Díaz del Arco, C.; Estrada Muñoz, L.; Molina Roldán, E.; Cerón Nieto, M.A.; Ortega Medina, L.; García Gómez de las Heras, S.; Fernández Aceñero, M.J. Immunohistochemical classification of gastric cancer based on new molecular biomarkers: A potential predictor of survival. Virchows Arch. 2018, 473, 687-695. [CrossRef]

17. Carlomagno, N.; Incollingo, P.; Tammaro, V.; Peluso, G.; Rupealta, N.; Chiacchio, G.; Sandoval Sotelo, M.L.; Minieri, G.; Pisani, A.; Riccio, E.; et al. Diagnostic, Predictive, Prognostic, and Therapeutic Molecular Biomarkers in Third Millennium: A Breakthrough in Gastric Cancer. Biomed. Res. Int. 2017, 2017, 7869802. [CrossRef]

18. Fanotto, V.; Ongaro, E.; Rihawi, K.; Avallone, A.; Silvestris, N.; Fornaro, L.; Vasile, E.; Antonuzzo, L.; Leone, F.; Rosati, G.; et al. HER-2 inhibition in gastric and colorectal cancers: Tangible achievements, novel acquisitions and future perspectives. Oncotarget 2016, 7, 60060-60074. [CrossRef]

19. Chivu-Economescu, M.; Matei, L.; Necula, L.G.; Dragu, D.L.; Bleotu, C.; Diaconu, C.C. New therapeutic options opened by the molecular classification of gastric cancer. World J. Gastroenterol. 2018, 24, 1942-1961. [CrossRef]

20. Boku, N. HER2-positive gastric cancer. Gastric Cancer 2014, 17, 423-430. [CrossRef]

21. Van Cutsem, E.; Bang, Y.J.; Feng-Yi, F.; Xu, J.M.; Lee, K.W.; Jiao, S.C.; Chong, J.L.; López-Sanchez, R.I.; Price, T.; Gladkov, O.; et al. HER2 screening data from ToGA: Targeting HER2 in gastric and gastroesophageal junction cancer. Gastric Cancer 2015, 18, 476-484. [CrossRef]

22. Tan, I.B.; Ivanova, T.; Lim, K.H.; Ong, C.W.; Deng, N.; Lee, J.; Tan, S.H.; Wu, J.; Lee, M.H.; Ooi, C.H.; et al. Intrinsic Subtypes of Gastric Cancer, Based on Gene Expression Pattern, Predict Survival and Respond Differently to Chemotherapy. Gastroenterology 2011, 141, 476-485. [CrossRef]

23. Kim, Y.; Cho, M.Y.; Kim, J.; Kim, S.N.; Oh, S.C.; Lee, K.A. Profiling cancer-associated genetic alterations and molecular classification of cancer in Korean gastric cancer patients. Oncotarget 2017, 8, 69888-69905. [CrossRef]

24. Marano, L.; Roviello, F. The distinctive nature of HER2-positive gastric cancers. Eur. J. Surg. Oncol. 2015, 41, 271-273. [CrossRef]

25. Ho, S.W.T.; Tan, P. Dissection of gastric cancer heterogeneity for precision oncology. Cancer Sci. 2019, 110, 3405-3414. [CrossRef]

26. Fiorillo, C.; Laterza, V.; Quero, G.; Menghi, R.; Cinaa, C.; Rosa, F.; Tortorelli, A.P.; Boskoski, I.; Alfieri, S. From biology to surgery: One step beyond histology for tailored surgical treatments of gastric cancer. Surg. Oncol. 2020, 34, 86-95. [CrossRef]

27. Lei, Z.; Tan, I.B.; Das, K.; Deng, N.; Zouridis, H.; Pattison, S.; Chua, C.; Feng, Z.; Guan, Y.K.; Ooi, C.H.; et al. Identification of molecular subtypes of gastric cancer with different responses to PI3-kinase inhibitors and 5-fluorouracil. Gastroenterology 2013, 145, 554-565. [CrossRef]

28. Bass, A.J.; Thorsson, V.; Shmulevich, I.; Reynolds, S.M.; Miller, M.; Bernard, B.; Hinoue, T. Comprehensive molecular characterization of gastric adenocarcinoma. Nature 2014, 513, 202-209. [CrossRef]

29. Ichikawa, H.; Nagahashi, M.; Shimada, Y.; Hanyu, T.; Ishikawa, T.; Kameyama, H.; Kobayashi, T.; Sakata, J.; Yabusaki, H.; Nakagawa, S.; et al. Actionable gene-based classification toward precision medicine in gastric cancer. Genome Med. 2017, 9, 93. [CrossRef]

30. Cristescu, R.; Lee, J.; Nebozhyn, M.; Kim, K.M.; Ting, J.C.; Wong, S.S.; Liu, J.; Yue, Y.G.; Wang, J.; Yu, K.; et al. Molecular analysis of gastric cancer identifies subtypes associated with distinct clinical outcomes. Nat. Med. 2015, 21, 449-456. [CrossRef]

31. Sun, Y.; Yu, W.; Guan, W.; Cai, L.; Qiao, M.; Zheng, L.; Jiang, R.; Wang, R.; Wang, L. Integrated assessment of PD-L1 expression and molecular classification facilitates therapy selection and prognosis prediction in gastric cancer. Cancer Manag. Res. 2019, 11, 6397-6410. [CrossRef] [PubMed]

32. Zhou, Y.J.; Zhu, G.Q.; Lu, X.F.; Zheng, K.Y.; Wang, Q.W.; Chen, J.N.; Zhang, Q.W.; Yan, F.R.; Li, X.B. Identification and validation of tumour microenvironment-based immune molecular subgroups for gastric cancer: Immunotherapeutic implications. Cancer Immunol. Immunother. 2020, 69, 1057-1069. [CrossRef] [PubMed]

33. Hang, X.; Li, D.; Wang, J.; Wang, G. Prognostic significance of microsatellite instability-associated pathways and genes in gastric cancer. Int. J. Mol. Med. 2018, 42, 149-160. [CrossRef] [PubMed] 
34. Yu, Y. Molecular classification and precision therapy of cancer: Immune checkpoint inhibitors. Front. Med. 2018, 12, 229-235. [CrossRef]

35. Di Pinto, F.; Armentano, R.; Arborea, G.; Schena, N.; Donghia, R.; Valentini, A.M. Are Immunohistochemical Markers Useful in Phenotypic Gastric Cancer Classification? Oncology 2020, 98, 566-574. [CrossRef]

36. Irkkan, C.; Balci, S.; Güler Tezel, G.; Akinci, B.; Yalcin, B.; Güler, G. Comparison of Clinicopathologic Parameters and Survivals Between Epstein-Barr Virus-positive and Her2-positive Gastric Cancers. Appl. Immunohistochem. Mol. Morphol. 2017, $25,609-614$. [CrossRef]

37. Fujimoto, M.; Matsuzaki, I.; Nishino, M.; Iwahashi, Y.; Warigaya, K.; Kojima, F.; Ono, K.; Murata, S.Y. HER2 is frequently overexpressed in hepatoid adenocarcinoma and gastric carcinoma with enteroblastic differentiation: A comparison of 35 cases to 334 gastric carcinomas of other histological types. J. Clin. Pathol. 2018, 71, 600-607. [CrossRef]

38. Gravalos, C.; Jimeno, A. HER2 in gastric cancer: A new prognostic factor and a novel therapeutic target. Ann. Oncol. 2008, 19, 1523-1529. [CrossRef]

39. Wang, Q.; Liu, G.; Hu, C. Molecular Classification of Gastric Adenocarcinoma. Gastroenterol. Res. 2019, 12, 275-282. [CrossRef]

40. Mathiak, M.; Warneke, V.S.; Behrens, H.M.; Haag, J.; Böger, C.; Krüger, S.; Röcken, C. Clinicopathologic Characteristics of Microsatellite Instable Gastric Carcinomas Revisited: Urgent Need for Standardization. Appl. Immunohistochem. Mol. Morphol. 2017, 25, 12-24. [CrossRef]

41. Smyth, E.C.; Wotherspoon, A.; Peckitt, C.; Gonzalez, D.; Hulkki-Wilson, S.; Eltahir, Z.; Fassan, M.; Rugge, M.; Valeri, N.; Okines, A.; et al. Mismatch Repair Deficiency, Microsatellite Instability, and Survival: An Exploratory Analysis of the Medical Research Council Adjuvant Gastric Infusional Chemotherapy (MAGIC). JAMA Oncol. 2017, 3, 1197-1203. [CrossRef]

42. Choi, Y.Y.; Kim, H.; Shin, S.J.; Kim, H.Y.; Lee, J.; Yang, H.K.; Kim, W.H.; Kim, Y.W.; Kook, M.C.; Park, Y.K.; et al. Microsatellite Instability and Programmed Cell Death-Ligand 1 Expression in Stage II/III Gastric Cancer: Post Hoc Analysis of the CLASSIC Randomized Controlled study. Ann. Surg. 2019, 270, 309-316. [CrossRef]

43. Martinson, H.A.; Mallari, D.; Richter, C.; Wu, T.T.; Tiesinga, J.; Alberts, S.R.; Olnes, M.J. Molecular Classification of Gastric Cancer among Alaska Native People. Cancers 2020, 12, 198. [CrossRef]

44. Laurén, P. The two histological main types of gastric carcinoma: Diffuse and so-called intestinal-type carcinoma. Acta Pathol. Microbiol. Scand. 1965, 64, 31-49. [CrossRef]

45. Bosman, F.T.; Carneiro, F.; Hruban, R.H.; Theise, N.D. WHO Classification of Tumours of the Digestive System, 4th ed.; World Health Organization: Geneva, Switzerland, 2010; ISBN 9789283224327.

46. Martín-Richard, M.; Carmona-Bayonas, A.; Custodio, A.B.; Gallego, J.; Jiménez-Fonseca, P.; Reina, J.J.; Richart, P.; Rivera, F.; Alsina, M.; Sastre, J. SEOM clinical guideline for the diagnosis and treatment of gastric cancer (GC) and gastroesophageal junction adenocarcinoma (GEJA) (2019). Clin. Transl. Oncol. 2020, 22, 236-244. [CrossRef]

47. Mariette, C.; Carneiro, F.; Grabsch, H.I.; van der Post, R.S.; Allum, W.; de Manzoni, G. Consensus on the pathological definition and classification of poorly cohesive gastric carcinoma. Gastric Cancer 2019, 22, 1-9. [CrossRef]

48. Li, G.C.; Jia, X.C.; Zhao, Q.C.; Zhang, H.W.; Yang, P.; Xu, L.L.; Pang, F.N.; Sun, J.B. The expression of epidermal growth factor receptor 1 and human epidermal growth factor receptor 2 based on tumor location affect survival in gastric cancer. Medicine 2020, 99, e20460. [CrossRef]

49. Rice, T.W.; Kelsen, D.P.; Blackstone, E.H.; Ishwaran, H.; Patil, D.T.; Bass, A.J.; Erasmus, J.J.; Gerdes, H.; Hofstetter, W.L. Esophagus and esophagogastric junction. In AJCC Cancer Staging Manual, 8th ed.; Amin, M.B., Ed.; Springer: New York, NY, USA, 2017; pp. 185-202. ISBN 9783319406176. [CrossRef]

50. Shitara, K.; Bang, Y.J.; Iwasa, S.; Sugimoto, N.; Ryu, M.H.; Sakai, D.; Chung, H.C.; Kawakami, H.; Yabusaki, H.; Lee, J.; et al. Trastuzumab Deruxtecan in Previously Treated HER2-Positive Gastric Cancer. N. Engl. J. Med. 2020, 18, 2419-2430. [CrossRef]

51. Polom, K.; Das, K.; Marrelli, D.; Roviello, G.; Pascale, V.; Voglino, C.; Rho, H.; Tan, P.; Roviello, F. KRAS Mutation in Gastric Cancer and Prognostication Associated with Microsatellite Instability Status. Pathol. Oncol. Res. 2019, 25, 333-340. [CrossRef]

52. Wang, Q.; Xie, Q.; Iu, Y.; Guo, H.; Ren, Y.; Li, J.; Zhao, Q. Clinical characteristics and prognostic significance of TCGA and ACRG classification in gastric cancer among the Chinese population. Mol. Med. Rep. 2020, 22, 828-840. [CrossRef]

53. Cai, L.; Sun, Y.; Wang, K.; Guan, W.; Yue, J.; Li, J.; Wang, R.; Wang, L. The Better Survival of MSI Subtype Is Associated With the Oxidative Stress Related Pathways in Gastric Cancer. Front. Oncol. 2020, 10, 1269. [CrossRef]

54. Vrána, D.; Matzenauer, M.; Neoral, C.; Aujeský, R.; Vrba, R.; Melichar, B.; Rušarová, N.; Bartoušková, M.; Jankowski, J. From Tumor Immunology to Immunotherapy in Gastric and Esophageal Cancer. Int. J. Mol. Sci. 2018, 20, 13. [CrossRef]

55. Ramos, M.F.K.P.; Pereira, M.A.; Amorim, L.C.; De Mello, E.S.; Faraj, S.F.; Ribeiro, U.; Hoff, P.M.G.; Cecconello, I.; De Castria, T.B. Gastric cancer molecular classification and adjuvanttherapy: Is there a different benefit according to the subtype? J. Surg. Oncol. 2020, 121, 804-813. [CrossRef]

56. Pinto, M.P.; Córdova-Delgado, M.; Retamal, I.N.; Muñoz-Medel, M.; Bravo, M.L.; Durán, D.; Villanueva, F.; Sanchez, C.; Acevedo, F.; Mondaca, S.; et al. A Molecular Stratification of Chilean Gastric Cancer Patients with Potential Clinical Applicability. Cancers 2020, 12, 1863. [CrossRef] [PubMed]

57. Smyth, E.C.; Nilsson, M.; Grabsch, H.I.; Van Grieken, N.C.; Lordick, F. Gastric cancer. Lancet 2020, 396, 635-648. [CrossRef]

58. Fuchs, C.S.; Doi, T.; Jang, R.W.; Muro, K.; Satoh, T.; Machado, M.; Sun, W.; Jalal, S.I.; Shah, M.A.; Metges, J.P.; et al. Safety and Efficacy of Pembrolizumab Monotherapy in Patients With Previously Treated Advanced Gastric and Gastroesophageal Junction Cancer: Phase 2 Clinical KEYNOTE-059 Trial. JAMA Oncol. 2018, 10, e180013. [CrossRef] [PubMed] 
59. Abbas, M.; Faggian, A.; Sintali, D.N.; Khan, G.J.; Naeem, S.; Shi, M.; Dingding, C. Current and future biomarkers in gastric cancer. Biomed. Pharmacother. 2018, 103, 1688-1700. [CrossRef]

60. Pereira, M.A.; Ramos, M.F.K.P.; Dias, A.R.; Faraj, S.F.; Ribeiro, R.R.E.; de Castria, T.B.; Zilberstein, B.; Alves, V.A.F.; Ribeiro, U., Jr.; de Mello, E.S. Expression Profile of Markers for Targeted Therapy in Gastric Cancer Patients: HER-2, Microsatellite Instability and PD-L1. Mol. Diagn. Ther. 2019, 23, 761-771. [CrossRef]

61. Ross, J.S.; Fakih, M.; Ali, S.M.; Elvin, J.A.; Schrock, A.B.; Suh, J.; Vergilio, J.A.; Ramkissoon, S.; Severson, E.; Daniel, S.; et al. Targeting HER2 in colorectal cancer: The landscape of amplification and short variant mutations in ERBB2 and ERBB3. Cancer 2018, 1, 1358-1373. [CrossRef]

62. Refolo, M.G.; Lotesoriere, C.; Messa, C.; Caruso, M.G.; D'Alessandro, R. Integrated immune gene expression signature and molecular classification in gastric cancer: New insights. J. Leukoc. Biol. 2020, 108, 633-646. [CrossRef] 